\title{
Finite Element Analysis of Osteotomy Treatment for Kienbock's Disease
}

\author{
Guang Yang1, Kimberly A. Partridge², Ahmed Abdel-Mohti ${ }^{3}$, Alex J. McMullen², Hui Shen²* \\ ${ }^{1}$ Department of Hand Surgery, China-Japan Union Hospital of Jilin University, Changchun, China \\ ${ }^{2}$ Department of Mechanical Engineering, Ohio Northern University, Ada, OH, USA \\ ${ }^{3}$ Department of Civil Engineering, Ohio Northern University, Ada, OH, USA \\ Email: *h-shen@onu.edu
}

How to cite this paper: Yang, G., Partridge, K.A., Abdel-Mohti, A., McMullen, A.J. and Shen, H. (2016) Finite Element Analysis of Osteotomy Treatment for Kienbock's Disease. J. Biomedical Science and Engineering, 9, 161-170.

http://dx.doi.org/10.4236/jbise.2016.910B021

Received: June 18, 2016

Accepted: September 20, 2016

Published: September 23, 2016

\begin{abstract}
Lateral closing wedge osteotomy is a treatment for Kienbock's disease. It is one of the most frequently used treatment options, which has been reported with relatively good long-term results. However, the results about the treatment are still controversial in some literatures and some key mechanisms are still not clear. The objective of the current study was to study the biomedical mechanism of the treatment. A finite element model was developed based on the geometry of carpal bones. Various situations including inclination angle changes by cutting the radial with $0^{\circ}, 5^{\circ}, 10^{\circ}$ and $15^{\circ}$ osteotomy angles were studied. The effectiveness of the treatment was also studied for the carpal structure with abnormal positions of the lunate bone. The results show that the effectiveness of the stress reduction with the angle depends on many situations such as the initial morphology of the carpal structure.
\end{abstract}

\section{Keywords}

Lateral Closing Wedge Osteotomy, Kienbock's Disease, Finite Element, Biomedical, Treatment

\section{Introduction}

The lunate bone is a carpal bone in the human hand. Kienbock's disease is the osteonecrosis of the lunate bone [1]. This disease was firstly termed by Robert Kienböck, an Austrian radiologist, in 1910 and was believed to be the consequence of the surrounding soft tissue trauma [2] [3]. Nowadays, although the aetiology and the progression history of the disease still remain unclear, the disease seems to be more frequently related to a biological vascular issue for blood flow affecting the lunate [1]. It might be affected by many factors such as morphological variations of carpus bones and trauma. 
It has been observed relatively more frequently in labor-intensive people and young individuals [4]-[8]. It was also reported that the disease could be caused by abnormal internal stresses on the lunate [9].

As for the treatment of the Kienbock's disease, many surgical options have been reported including ulna lengthening or radial shortening, capitate shortening, lunate resection, and radial wedge osteotomy [10] [11]. The short-term effect has been studied experimentally and analytically, and the long-term effect has been studied with following-up studies [9] [10] [12] [13]. Although many researchers have conducted various studies on the effectiveness of treatments, the conclusion of which one is the most effective is still controversial. Among all the treatments, radial closing wedge osteotomy, as shown in Figure 1, is one of the most frequently used treatment options, which has been reported with better long term results than some other treatments by some researchers [2] [14]-[20]. The operation is to cut a wedge on the radius to change the inclination angle of the radius bone. However, the results about the treatment are still controversial in some literatures and some key mechanisms are still not clear. While it was showed the load on lunate could be relieved by the operation by some researchers [21], some other researchers reported increased load on the lunate after the operation [22]. To resolve the conflict, Kam et al. measured the load on lunate with strain gauge [23]. However, their results also showed increased strain with the wedge cut angle. They couldn't explain the satisfactory clinical results. As for the angle of the wedge cut on the radial bone. Tsumura et al. (1984) recommended cutting the distal radius by an approximately 15-degree wedge, but Kojima et al. recommended 5 degrees [19] [24].

Based on the literature review, it seems that there is no consistent conclusion on the effectiveness of the osteotomy treatment and on the optimum angle of the wedge that should be cut on the radial bone. Therefore, the objective of the current work is to study how the stress distribution changes on the lunate bone and the surrounding cartilages with the radial inclination. Finite element models were developed in the study to demonstrate how the stress distributions were affected by various factors.

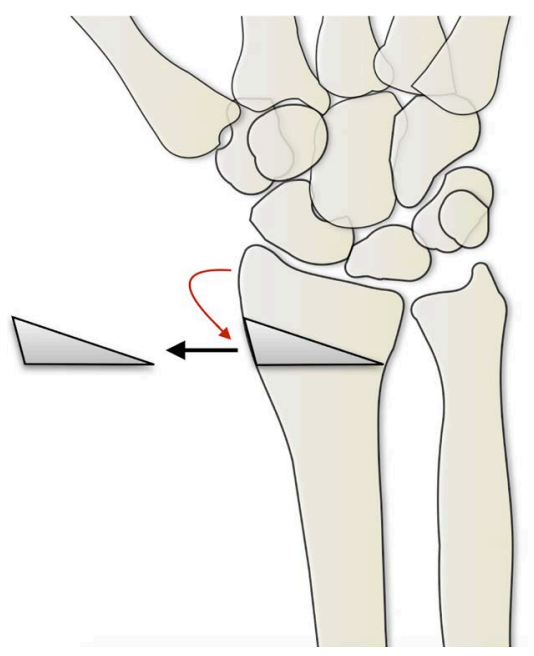

Figure 1. Radial close wedge osteotomy for Kienbock's disease. 


\section{Finite Element Models}

To obtain the full field solution of the stress distribution of the lunate bone, two-dimensional finite element models were developed using software ANSYS [25]. The geometry of the model was created by tracing an anteriorposterior X-ray of the carpal joint. This geometry development method was used by Ledoux et al. in 2001 and 2008 to study the biomechanics mechanism of the Kienbock's disease and fracture of the scaphoid bone [26] [27]. The X-ray picture, as shown in Figure 2(a), and CT scan model as shown in Figure 2(b), were obtained from a right carpal joint of a 19 years old man without Kienbock's disease.

To simplify the extremely complicated carpal joint structure, only the scaphoid, lunate, ulna and radius bones were used in the model and the lunate bone contacts with radius and ulna bones with cartilages. It was believed the abnormal radial inclination, uncovering of the lunate, and the relative position of the lunate could be the factors that lead to the disease [1]. Therefore, three (types of) FE models were developed as shown in Figure 3. The geometry of the first model (model 1) in Figure 3(a) was created based on healthy carpal joint in Figure 2(a). The second model (model 2), as shown in Figure 3(b), was created off the healthy model (model 1 ) by tilting the lunate bone 15 degrees counterclockwise to simulate the abnormal radial inclination. The third model (model 3) was developed by shifting the lunate bone in the second model horizontally to the right by $1.5 \mathrm{~mm}, 3 \mathrm{~mm}$, and $4.5 \mathrm{~mm}$. This model is based on one $\mathrm{x}$-ray picture of a patient with Kienbock's disease in [28]. The one with $3 \mathrm{~mm}$ shift is shown in Figure $3(c)$. The third model is to simulate different covering and relative position of the lunate. The effect of radial inclination (wedge cut) was studied using the first two models. It was assumed that the radial bone has a wedge cut of $0^{\circ}, 5^{\circ}, 10^{\circ}$, and $15^{\circ}$ to simulate the operation. The first variation was with no cut in the radius bone to simulate a control model. The radius inclination angle for the control models is $22^{\circ}$ for both the models.

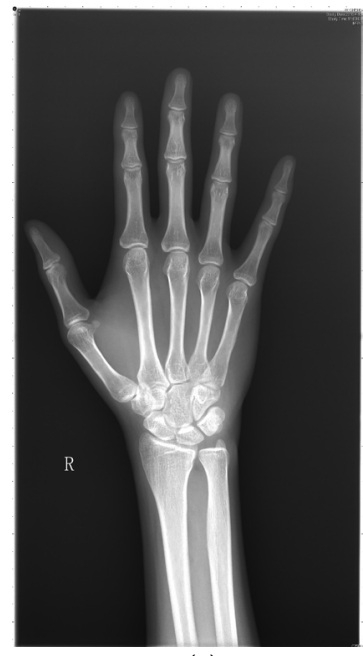

(a)

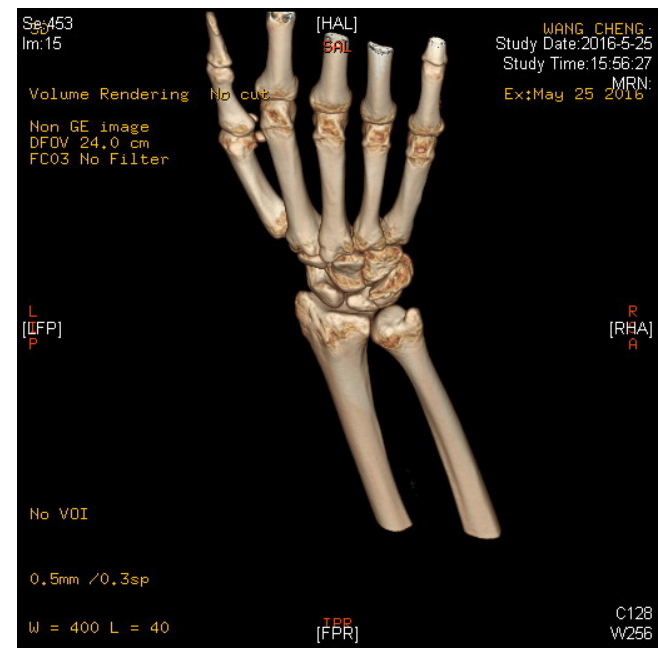

(b)

Figure 2. (a) X-ray and (b) CT scan pictures of a 19-year-old man's right carpal joint. 


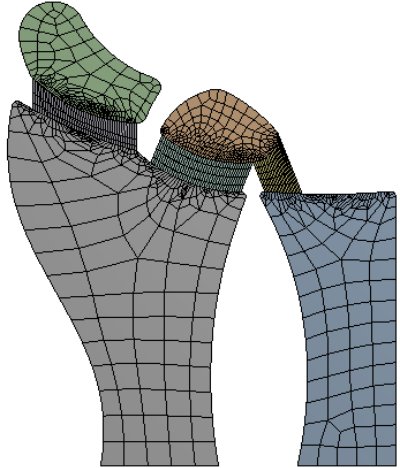

(a)

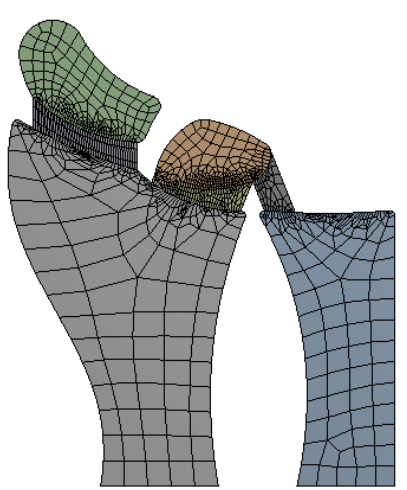

(b)

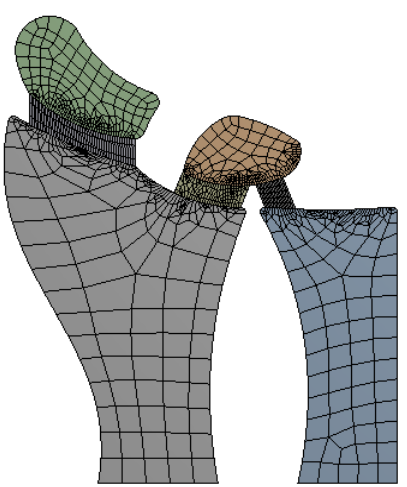

(c)

Figure 3. Finite element model of the wrist bones of radius, ulna, and lunate bones.

For all the models, cartilages were assumed to be bonded between the contact surfaces of the four bones. Fixed boundary conditions were applied at the bottom of radius and ulna bones to constrain the model. Forces of $40 \mathrm{~N}$ and $60 \mathrm{~N}$ were applied in the downward direction on the top of the scaphoid and lunate bone, respectively. The lunate, radius, ulna, and scaphoid bones were simulated as homogenous elastic cancellous material with Young's modulus of 18,000 MPa and Poisson's ratio of 0.2 [26] [27]. The cartilage has a Young's modulus of $10 \mathrm{MPa}$ with the Poisson's ratio of 0.49 to assume the near non-compressibility of the cartilage [29]. Mesh convergence was verified based on results.

\section{Results and Discussion}

\subsection{Results}

As the minimum principal stress detonates the maximum value of the compression stress under the compression load in the models, the minimum principal stress was compared for model 1 with osteotomy (wedge cut) angles of $0^{\circ}$ (control model), $5^{\circ}, 10^{\circ}$ and $15^{\circ}$. The stress distributions of model 1 are shown in Figures 4(a)-(d) and for model 2 Figures 5(a)-(d). The stress distributions of models 3 are shown in Figure 6 with different shift distances.

While it can be seen that stress distribution changes with different osteotomy angles and shift distance in Figures 4-6, the stress values were compared for the stresses at different locations to demonstrate the effect. Figure 7 shows the location of the different points in the models where the principal stress values were extracted. The values were then compared and reported as a percentage of control at various locations. The control sample is model 1 with $0^{\circ}$ osteotomy angle that has the percentage of $100 \%$. Other models were compared with the value for this model at the corresponding point.

Figure 8 shows the minimum principle stress for each angular inclination and shift expressed as a percentage of control for points 3 and 5 in lunate bone. It can be observed from model 1 that at the bottom (point 3 ) the stress value decreases as the wedge osteotomy angle increase. The value is $90.0 \%, 85.7 \%$, and $92.3 \%$ of the control model. The stress value is the lowest at $10^{\circ}$. For the center point 5 , same trend was observed. 


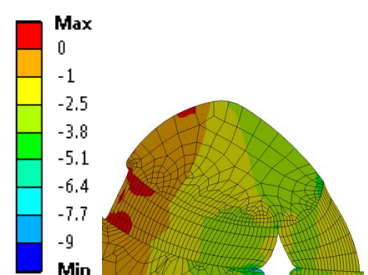

(a)

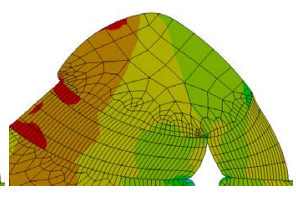

(b)

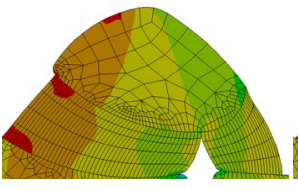

(c)

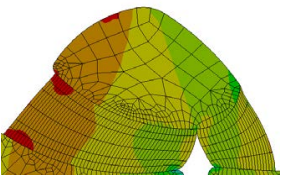

(d)

Figure 4. Minimum principal stress distribution for model 1 with osteotomy angle of (a) $0^{\circ}$, (b) $5^{\circ}$, (c) $10^{\circ}$, and (d) $15^{\circ}$.

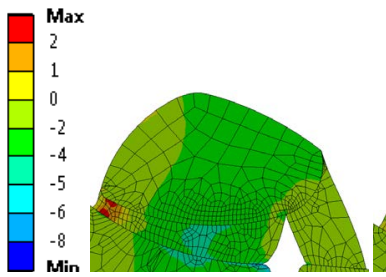

(a)

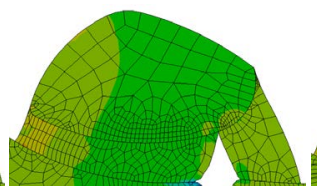

(b)

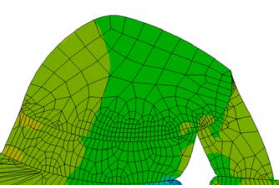

(c)

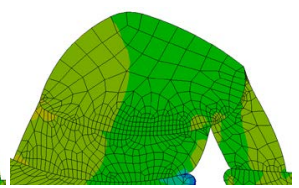

(d)

Figure 5. Minimum principal stress distribution for model 2 with osteotomy angle of (a) $0^{\circ}$, (b) $5^{\circ}$, (c) $10^{\circ}$, and (d) $15^{\circ}$.
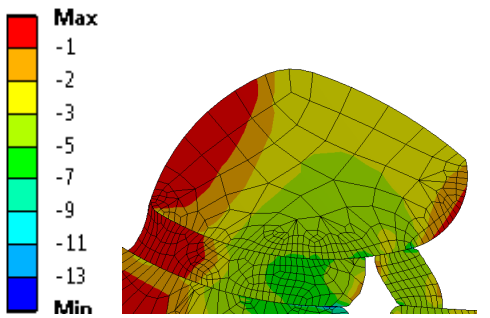

(a)

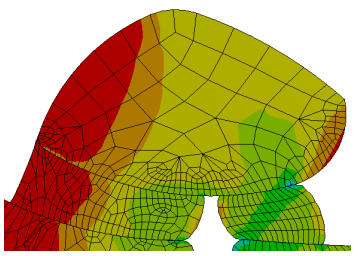

(b)

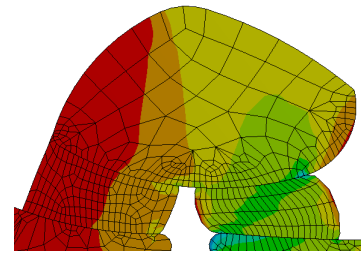

(c)

Figure 6. Minimum principal stress distribution for model 3 with lunate bone shifting by (a) 1.5 $\mathrm{mm}$, (b) $3 \mathrm{~mm}$, and (c) $4.5 \mathrm{~mm}$.

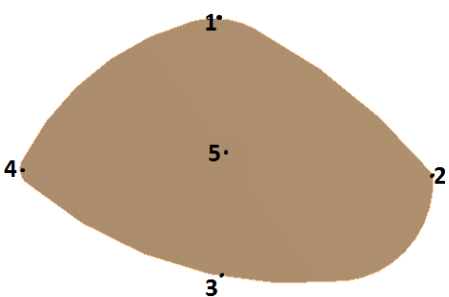

(a)

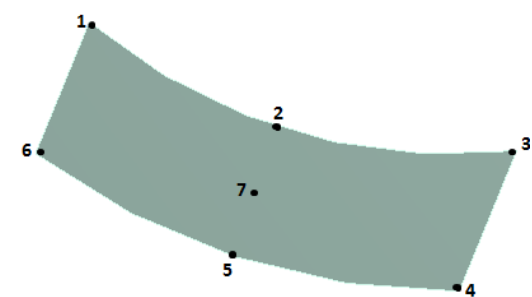

(b)

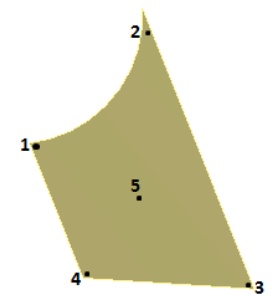

(c)

Figure 7. The locations for the points that were used to extract stress values: (a) lunate bone model, (b) cartilage between lunate and radius bone, and (c) cartilage between lunate and ulna bone.

Compared to model 1 which is for the carpal structure of a person without the disease, the stress values of model 2 at corresponding points are much higher than the control model. For point 3 in model 2, before the surgery, the stress is $139.7 \%$ of the control, which decreases with the angle. They are $125.6 \%$ at $5^{\circ}, 104.7 \%$ at $10^{\circ}$, and $105.8 \%$ at $15^{\circ}$. 
Lunate Point 3

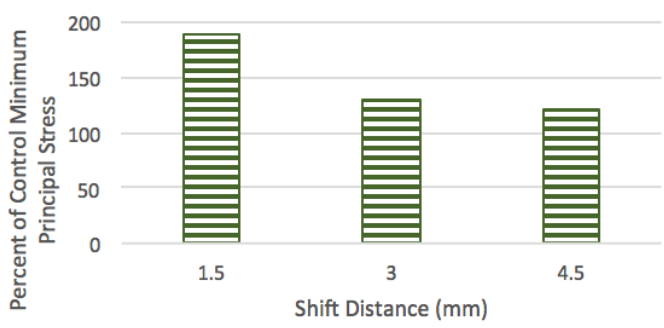

(a)

Lunate Point 3

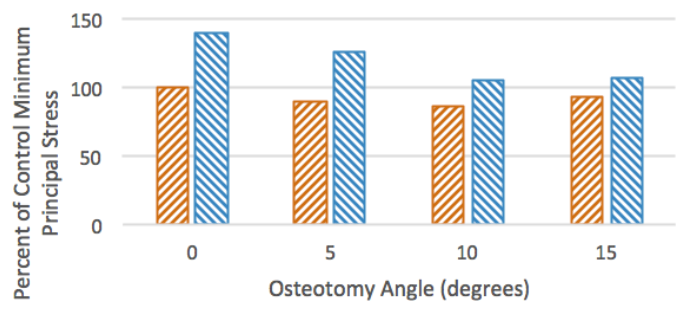

(c)
Lunate Point 5

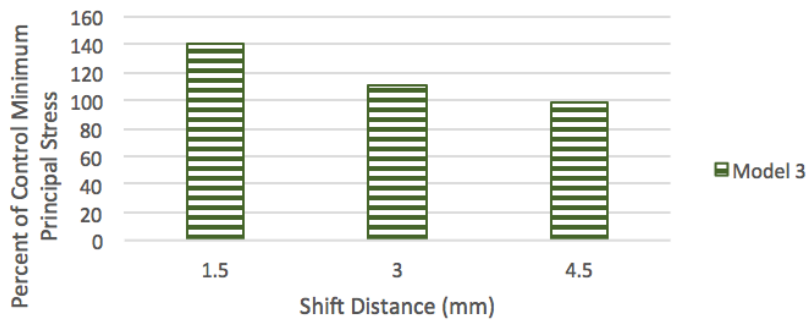

(b)

Lunate Point 5

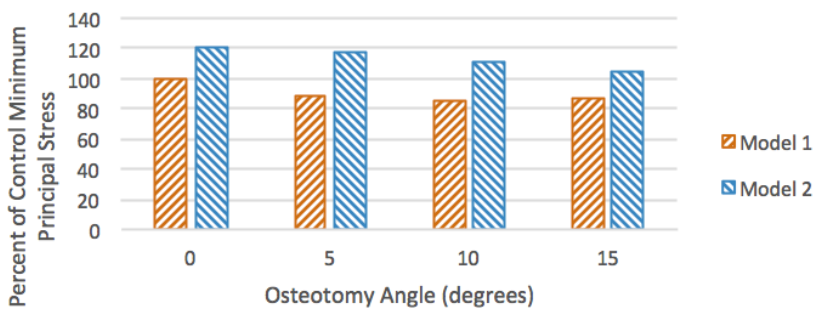

(d)

Figure 8. The minimum principle stress for each angular inclination and shift expressed as a percentage of control for points 3 and 5 in lunate bone: (a) point 3 for model 1 and 2, (b) point 5 for model 1 and 2, (c) point 3 for model 3, and (d) point 5 for model 3.

That is, the stress reaches minimum at $10^{\circ}$. For point 5 in model 2 , the stress value keeps decreasing with the angle from $120.8 \%$ at $0^{\circ}$ to $104.9 \%$ at $15^{\circ}$. As the lunate bone shifts $1.5 \mathrm{~mm}$, the stress values are much higher than the control one for the two points. The $187.9 \%$ and $140.6 \%$ of the control at point 3 and 5, respectively, as the lunate shift for $1.5 \mathrm{~mm}$. While as it shifts further, the value become smaller, but most values are still higher than the control.

As stated in [1], the aetiology of the Kienbock's disease is very complicated. As many factors including the uncovering of the lunate affect the disease, the stress in the cartilage was also investigated as shown in Figure 9 and Figure 10. As can be seen for model 1 in the cartilage between lunate and radius bone, the stress values for points 5 and 7 decrease and then increase with the angle. The values for model 2 are much higher than the control, which was $189.3 \%$ and $219.2 \%$ before osteotomy. That is, the abnormity of the structure cause higher stress in the cartilage, which might cause the disease in the long term. The stress decreases as the angle of osteotomy increases. The stress at the center point of the cartilage between lunate and ulna bone (Figure 10) shows that there is small change (maximum $106.3 \%$ at $10^{\circ}$ ) for model 1 with the angle, but the stresses are lower than control for model 2 which is reasonable as the stress of the cartilage on other side (between lunate and radius bone) increases. That is, the load shifts to the cartilage on the other side.

\subsection{Discussion}

The radial closing wedge osteotomy surgery intends to reduce the load on lunate. The 


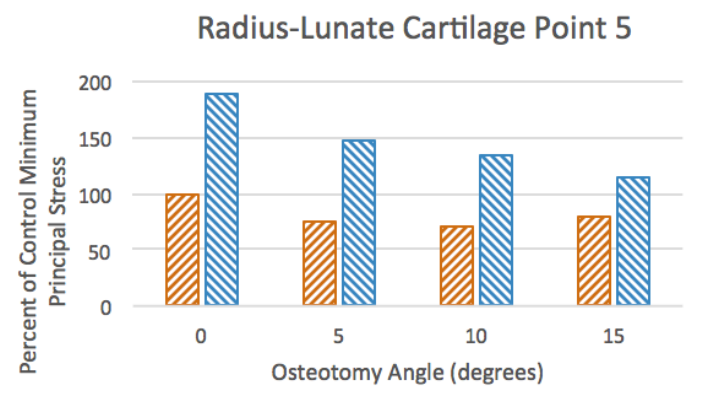

(a)

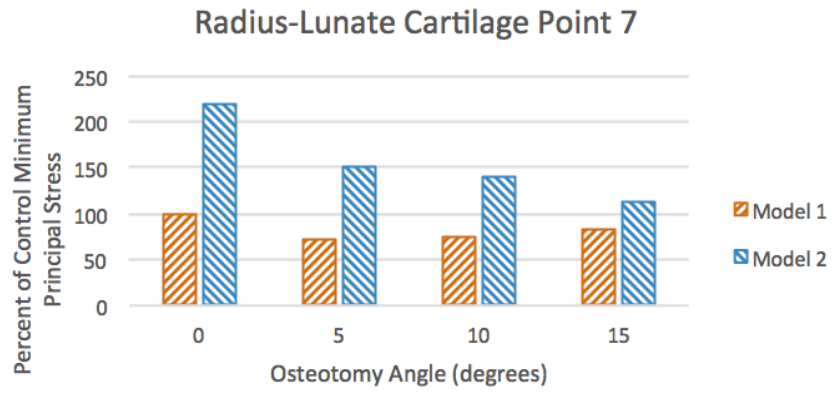

(b)

Figure 9. The minimum principle stress for each angular inclination in models 1 and 2 expressed as a percentage of control (100\%) for (a) point 5 and (b) point 7 in cartilage between lunate and radius bone.

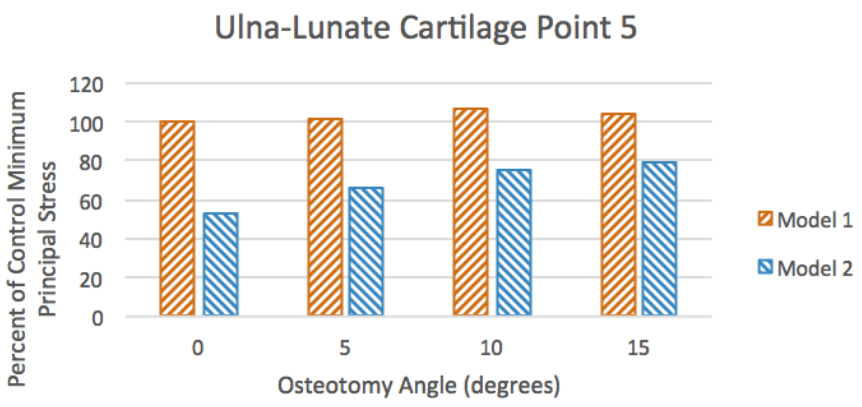

Figure 10. The minimum principle stress for each angular inclination in models 1 and 2 expressed as a percentage of control (100\%) for point 5 in cartilage between lunate and ulna bone.

clinical results showed the treatment was effective [14]-[20]. However, the biomedical mechanism of the treatment has been debated for years. Watanabe et al. showed the load on lunate was reduced by the radial closing wedge osteotomy using a $2 \mathrm{D}$ mathematical model [20]. Werner and Palmer found the pressure increased on lunate using pressure-sensitive film measurement [22]. To resolve the debate, Kam et al. used strain gauges to measure the compression strain on the lunate bone directly and found the increased strain on the lunate bone as the angle changed with radial closing wedge osteotomy [23]. They realized the limitation of their methodology as the strain gauges only measured one point but not the entire filed of the lunate bone.

The current study still made the effort to resolve the debate and looked into the biomedical mechanism of the treatment. The results showed that the effectiveness of the stress reduction with the angle depends on many situations such as the initial morphology of the carpal structure. For example, in model 1, the stress changes with the angle, but not very significant. However, if started with the initial position of the lunate in model 2, the stress is much higher than the control, which is $139.7 \%$ of the control. The stress value decreases greatly with the angle to $104.7 \%$ at $10^{\circ}$ for point 3 . Stress value at point 5 reduces from $120.8 \%$ at $0^{\circ}$ to $104.9 \%$, which is not as significant as point 3. It should be pointed out that in the previous studies [20] [22] [23], only a limited number of cadaver specimens were used to measure the force either on one specific surface or a point. The limitation on the specimens and methodology might have 
resulted in the controversial observations based on our current results.

There are some limitations of the current study that should be mentioned herein. For the material properties of the bone and cartilage, they were assumed to be homogenous elastic. While these properties were obtained from other literatures [26] [27] [29], the assumption still applied limitations on the models. However, we think the trend of the results is still valid as the purpose of the study was to compare stresses in different situations of the lunate.

\section{References}

[1] Schuind, F., Eslami, S. and Ledoux, P. (2008) Kienböck's Disease. Bone and Joint Journal, 90-B, 133-139. http://dx.doi.org/10.1302/0301-620x.90b2.20112

[2] Peltier, L.F. (1980) The Classic: Concerning Traumatic Malacia of the Lunate and Its Consequences: Degeneration and Compression Fractures. Clinical Orthopaedics and Related Research, 149, 4-8.

[3] Ståhl, F. and Brown, L.J. (1947) On Lunatomalacia (Kienböck's Disease): A Clinical and Roentgenological Study, Especially on Its Pathogenesis and Late Results of Immobilization Treatment. Acta Chir. Scandinavica (Supplementum), 126, 1-133.

[4] Almquist, E.E. and Burns Jr., J.F. (1982) Radial Shortening for the Treatment of Kienbock's Disease-A 5- to 10-Year Follow-Up. Journal of Hand Surgery, 7, 348-352. http://dx.doi.org/10.1302/0301-620x.90b2.20112

[5] Axelsson, R. and Moberg, E. (1988) The Treatment of Kienbock's Disease and the Role of Joint Leveling Operations. In: Razemon, J.P. and Fisk G.R., Eds., The Wrist, Churchill Livingstone, Edinburg and New York, 194-201.

[6] Cooney, W.P., Bussey, R., Dobyns, J.H. and Linscheid, R.L. (1987) Difficult Wrist Fractures. Perilunate Fracture Dislocations of the Wrist. Clinical Orthopaedics and Related Research, 214, 136-147.

[7] Hulten, O. (1928) U'ber anatomische Variation der Handgelenkknochen. Acta Radiologica, 9, 155-168. http://dx.doi.org/10.3109/00016922809176658

[8] Keith, P.P., Nuttall, D. and Trail, I. (2004) Long-Term Outcome of Nonsurgically Managed Kienbock's Disease. Journal of Hand Surgery, 29A, 63-67. http://dx.doi.org/10.1016/j.jhsa.2003.10.016

[9] Ledoux, P., Lamblin, D., Wuilbaut, A. and Schuind, F. (2008) A Finite-Element Analysis of Kienbock's Disease. The Journal of Hand Surgery, 33E, 286-291. http://dx.doi.org/10.1177/1753193408090757

[10] Horii, E., Garcia-Elias, M., An, K.N., Bishop, A.T., Cooney, W.P., Linscheid, R.L. and Chao, E.Y.S. (1990) Effect on Force Transmission across the Carpus in Procedures Used to Treat Kienbiick's Disease. The Journal of Hand Surgery, 15, 393-400. http://dx.doi.org/10.1016/0363-5023(90)90049-W

[11] Nakamura, R., Nakao, E., Nishizuka, T., Takahashi, S. and Koh, S. (2011) Radial Osteotomy for Kienbock Disease. Techniques in Hand \& Upper Extremity Surgery, 15, 48-54. http://dx.doi.org/10.1097/BTH.0b013e31820baa36

[12] Trumble, T., Glisson, R.R., Seaber, A.V. and Urbaniak, J.R. (1986) A Biomechanical Comparison of the Methods for Treating Kienbock's Disease. The Journal of Hand Surgery, 11, 88-93. http://dx.doi.org/10.1016/S0363-5023(86)80111-3

[13] Iwasaki, N., Genda, E., Minami, A., Kaneda, K. and Chao, E.Y. (1998) Force Transmission 
through the Wrist Joint in Kienbock's Disease: A Two-Dimensional Theoretical Study. The Journal of Hand Surgery, 22, 415-424. http://dx.doi.org/10.1016/S0363-5023(05)80459-9

[14] Koh, S., Nakamura, R., Horii, E., Nakao, E., Inagaki, H. and Yajima, H., (2003) Surgical Outcome of Radial Osteotomy for Kienbock's Disease-Minimum 10 Years of Follow-Up. The Journal of Hand Surgery, 28, 910-916. http://dx.doi.org/10.1016/S0363-5023(03)00490-8

[15] Masear, V.R., Zook, E.G., Pichora, D.R., Russell, R.C., Lemons, J. and Bidez, M.W. (1992) Strain-Gauge Evaluation of Lunate Unloading Procedures. Journal of Hand Surgery, 17A, 437-442. http://dx.doi.org/10.1016/0363-5023(92)90344-O

[16] Trumble, T., Glisson, R.R., Seaber, A.V. and Urbaniak, J.R. (1986) A Biomechanical Comparison of the Methods for Treating Kienbock's Disease. Journal Hand Surgery, 11A, 88-93. http://dx.doi.org/10.1016/S0363-5023(86)80111-3

[17] Horii, E., Garcia-Elias, M., An, K.N., et al. (1990) Effect on Force Transmission across the Carpus in Procedures Used to Treat Kienbock's Disease. Journal of Hand Surgery, 15A, 393-400. http://dx.doi.org/10.1016/0363-5023(90)90049-W

[18] Wada, A., Miura, H., Kubota, H., Iwamoto, Y., Uchida, Y. and Kojima, T. (2002) Radial Closing Wedge Osteotomy for Kienbock's Disease: An over 10 Year Clinical and Radiographic Follow-Up. Journal of Hand Surgery, 27B, 175-179. http://dx.doi.org/10.1054/jhsb.2001.0621

[19] Tsumura, H., Himeno, S., Morita, H., et al. (1984) The Optimum Correcting Angle of Wedge Osteotomy at the Distal End of the Radius for Kienbock's Disease. J Jpn Soc Surg Hand, 1, 435-439.

[20] Nakamura, R., Watanabe, K., Tsunoda, K. and Miura, K. (1993) Radial Osteotomy for Kienbock's Disease Evaluated by Magnetic Resonance Imaging, 24 Cases Followed for 1-3 Years. Acta Orthopaedica Scandinavica, 64, 207-211. http://dx.doi.org/10.3109/17453679308994572

[21] Watanabe, K., Nakamura, R., Horii, E. and Miura, T. (1993) Biomechanical Analysis of Radial Wedge Osteotomy for the Treatment of Kienbock's Disease. Journal of Hand Surgery, 18A, 686-690. http://dx.doi.org/10.1016/0363-5023(93)90319-X

[22] Werner, F.W. and Palmer, A.K. (1993) Biomechanical Evaluation of Operative Procedures to Treat Kienbock's Disease. Hand Clinics, 9, 431-442.

[23] Kam, B., Topper, S.M., McLoughlin, S. and Liu, Q. (2002) Wedge Osteotomies of the Radius for Kienbock's Disease: A Biomechanical Analysis. The Journal of Hand Surgery, 27, 37-42. http://dx.doi.org/10.1053/jhsu.2002.29489

[24] Kojima, T., Uchida, Y., Kido, M., Sinohara, N. and Tsumura, H. (1985) The Results of the Wedge Osteotomy of Radius in the Treatment of Kienbock's Disease. J Jpn Sot Surg Hand, 2, 435-438.

[25] ANSYS Simulation Software, Ansys Inc.

[26] Ledoux, P., Lamblin, D. and Targowski, R. (2001) Modifications to the Mechanical Behavior of the Wrist after Fracture of the Scaphoid. Modeling by Finite Element Analysis. Acta Orthopaedica Belgica, 67, 236-241.

[27] Ledoux, P., Lamblin, D., Wuilbaut, A. and Schuind, F. (2008) A Finite Element Analysis of Kienbock's Disease. The Journal of Hand Surgery, 33E, 286-291. http://dx.doi.org/10.1177/1753193408090757

[28] Soejima, O., Iida, H., Komine, S., Kikuta, T. and Naito, M. (2002) Lateral Closing Wedge Osteotomy of the Distal Radius for Advanced Stages of Kienbock's Disease. The Journal of 
Hand Surgery, 27A, 31-36. http://dx.doi.org/10.1053/jhsu.2002.30906

[29] Edwards, W.B. and Troy, K.L. (2012) Finite Element Prediction of Surface Strain and Fracture Strength at the Distal Radius. Medical Engineering \& Physics, 34, 290-298.

http://dx.doi.org/10.1016/j.medengphy.2011.07.016

Submit or recommend next manuscript to SCIRP and we will provide best service for you:

Accepting pre-submission inquiries through Email, Facebook, LinkedIn, Twitter, etc. A wide selection of journals (inclusive of 9 subjects, more than 200 journals)

Providing 24-hour high-quality service

User-friendly online submission system

Fair and swift peer-review system

Efficient typesetting and proofreading procedure

Display of the result of downloads and visits, as well as the number of cited articles Maximum dissemination of your research work

Submit your manuscript at: http://papersubmission.scirp.org/

Or contact jbise@scirp.org 